EESTI NSV TEADUSTE AKADEEMIA TOIMETISED. XV KÖIDE FOOSIKA-MATEMAATIKA- JA TEHNIKATEADUSTE SEERIA, 1966, NR. 2

ИЗВЕСТИЯ АКАДЕМИИ НАУК ЭСТОНСКОЙ ССР. ТОМ ХV

СЕРИЯ ФИЗИКО-МАТЕМАТИЧЕСҚИХ И ТЕХНИЧЕСКИХ НАУК. 1966, № 2

О. КИРРЕТ, Э. КЮЛЛИК

\title{
КАЧЕСТВЕННЫЙ АНАЛИЗ ВОЛОКОН МЕТОДОМ ПИРОЛИЗНОЙ ГАЗОВОЙ ХРОМАТОГРАФИИ
}

При анализе различных соединений в последнее время наряду с газовой хроматографией все большее применение находит пиролизная газовая хроматография [1].

Особенное значение приобретает этот метод при анализе высококипящих соединений, которые невозможно анализировать методом газо-жидкостной хроматографии. Қроме того, он позволяет более детально исследовать механизм пиролитического разложения.

В некоторых работах пиролизная газовая хроматография использована для идентиф́ккации полимеров [2-4] и эластомеров [5], среди которых были и некоторые случайно выбранные волокна. Однако в литературе отсутствуют данные об единой системе и методике качественного анализа волокон методом пиролизной газовой хроматографии.

В одной более ранней статье авторы настоящей работы представили результаты, полученные при пиролизе и идентификации некоторых волокон [6].

Выработанная система и методика пиролизной газовой хроматографии позволила идентифицировать волокна по основным группам, но не дала возможности разделить волокна, которые дали при пиролизе почти одинаковые продукты (шерсть, натуральный шелк, полиамиды, целлюлоза и ее производныс)

В данной работе более подробно исследован пиролиз ряда волокон в различных условиях и представлена единая система для их идентификации.

\section{Методика анализа}

В работе использовался универсальный газовый хроматограф УХ-1 в сочетании с ранее разработанной контролируемой системой пиролиза [7]. Во избежание возможных каталитических процессов при пиролизе медный блок для пиролиза был заменен блоком из нержавеющей стали.

В зависимости от элементарного состава волокон и механизма их термического разложения в процессе пиролиза могут получаться различные группы соединений (парафины, олефины, спирты и т. д.), четкое распределение которых способствует точности анализа.

При выборе пригодных наполнителей колонок использовались следуюшие стационарные фазы: силиконовое масло, апиезон L, диметилформамид, сквалан, $\beta, \beta^{\prime}$-тиодипропионитрил, полиэтиленгликоль и др. $\mathrm{B}$ качестве твердого носителя применялся преимущественно хромосорб $\mathrm{P}$. Для разделения легких газовых продуктов использовались колонки с активным углем и силикагелем. При этом лучшие результаты дали, полиэтиленгликоль и активный уголь. 
Условия хроматографнческого разделения продуктов пиролиза:

1) колонка размером $400 \times 0,39$ см, наполнитель - полиэтиленгликоль 1000 на хромосорбе P (35-80 меш) в соотношении $25: 75$, температура колонки $100^{\circ} \mathrm{C}$, скорость газа-носителя (гелия) - 3,8 $/$ час;

2) колонка размером $600 \times 0,36 \mathrm{~cm}$, наполнитель - активный уголь, температура колонки $46^{\circ}$, скорость гелия - 4,5 лічас.

У словия пи роли з а: время - 10-12 сек, количество пробы$1,7-3,0$ мг, температуры - 300, 400, 500, 700 и $900^{\circ}$; процесс проводился в токе газа-носителя.

Все волокна были предварительно очищены этанолом и эфиром и высушены при температуре $105^{\circ}$ (кроме поливинилхлорида и полиэтиліена).

В работе были исследованы 17 различных волокон и полиэтилен в гранулах. Оптимальной температурой пиролиза оказалась $500^{\circ}$, при ксторой были получены наиболее характерные хроматограммы.

Предварительная интерпретация хроматограмм показала, что хроматограммы всех проанализированных волокон (кроме полифена), наряду с другими пиками, всегда имеют два пика, время удерживания которых постоянно.

С помощью препаративной газовой хроматографии были выделены продукты, соответствующие этим пикам. Затем было проведено их определение четырьмя методами: 1) идентификацией функциональных групп $\left.\left[{ }^{8}\right], 2\right)$ инфракрасным спектральным анализом, 3) ультрафиолетовым спектральным анализом, 4) по временам удерживания.

Эти два продукта оказались бензолом и толуолом. Из них бензол четко выражен на хроматограммах. Содержание бензола в пиролизных продуктах всех исследованных волокон позволяет использовать его в качестве внутреннего стандарта.

Основой расчета времени удерживания служил момент появления первого пика, расстояние которого от пика бензола было принято равным 100.

Хроматограммы волокон, пиролизованных при $500^{\circ}$, представлены на рис. 1, а времена удерживания всех пиков в отношении бензола в таблице.

При интерпретации хроматограмм нужно иметь в виду, что изменения количества пиролизованного вещества может вызвать изменение в хроматограммах. Во избежание этого нужно всегда использовать равные количества пробы. Следует также иметь в виду, что эффективность анализа зависит от рабочего режима хроматографа.

\section{Результаты исследования}

По внешнему виду хроматограммы пиролиза можно разделить на четыре основные группы (см. рис. 1 и таблицу).

1. Шерсть, натуральный шелк, полиамиды (капрон, анид, энант, ундекан) имеют характерные пики $(24,29,30,32)$ и расплывчатый пик в конце хроматограммы. Время удерживания этого пика совпадает со временем удерживания воды.

2. Хлопок, лен, производные целлюлозы (пики $15,16,20,22,24,25$ ).

3. Нитрон, хлорин, полиэтилен, полипропилен, полифен и др., кото- 
Относительные-времена удерживания

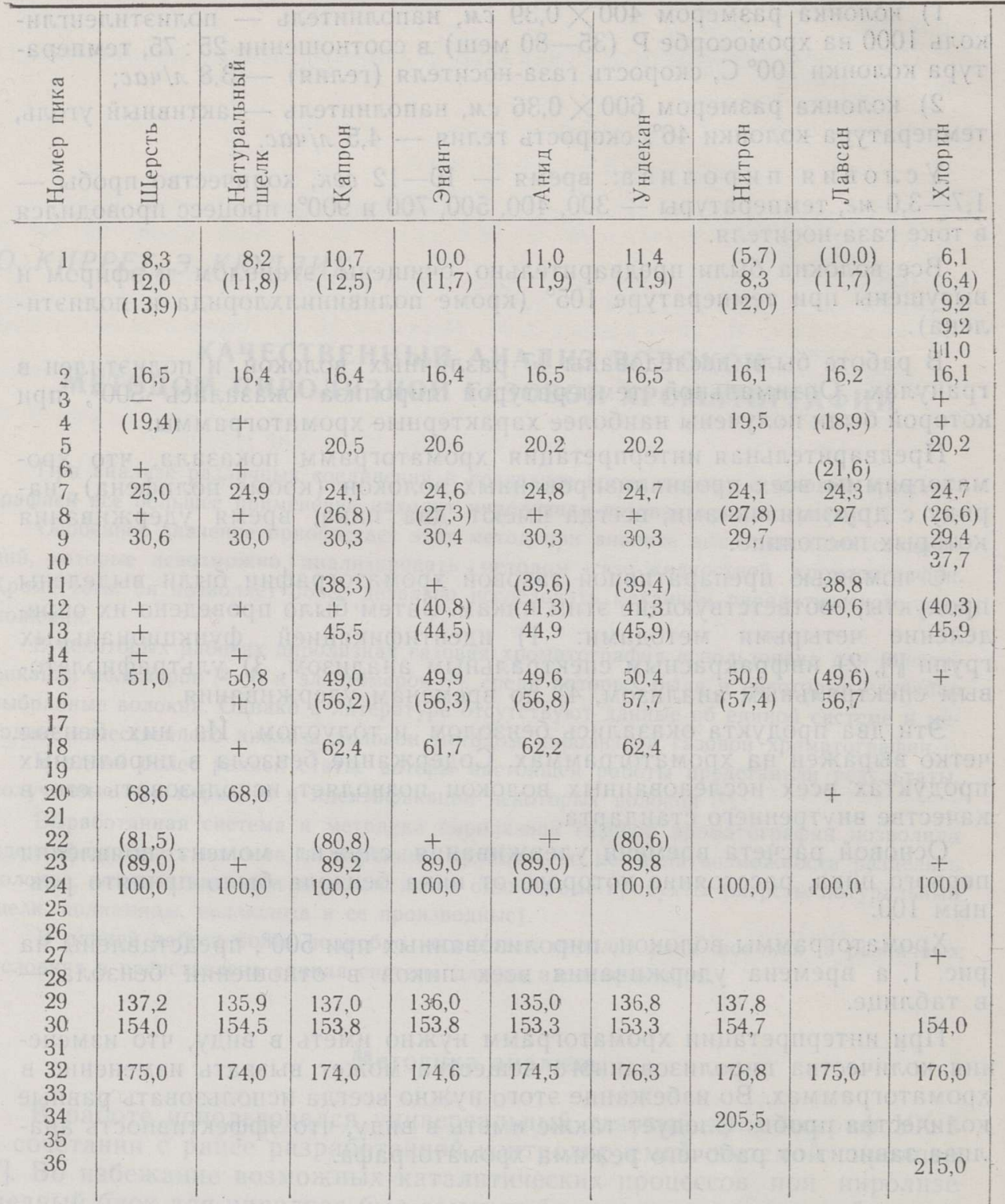

Пр и меча ния. 1. Пик, обозначенный номером 1 , характеризует несколько трудноотделимых друг от друга компонентов.

2. В скобках приведены значения относителыно малых пиков. 


\section{продуктов пиролиза волокон}

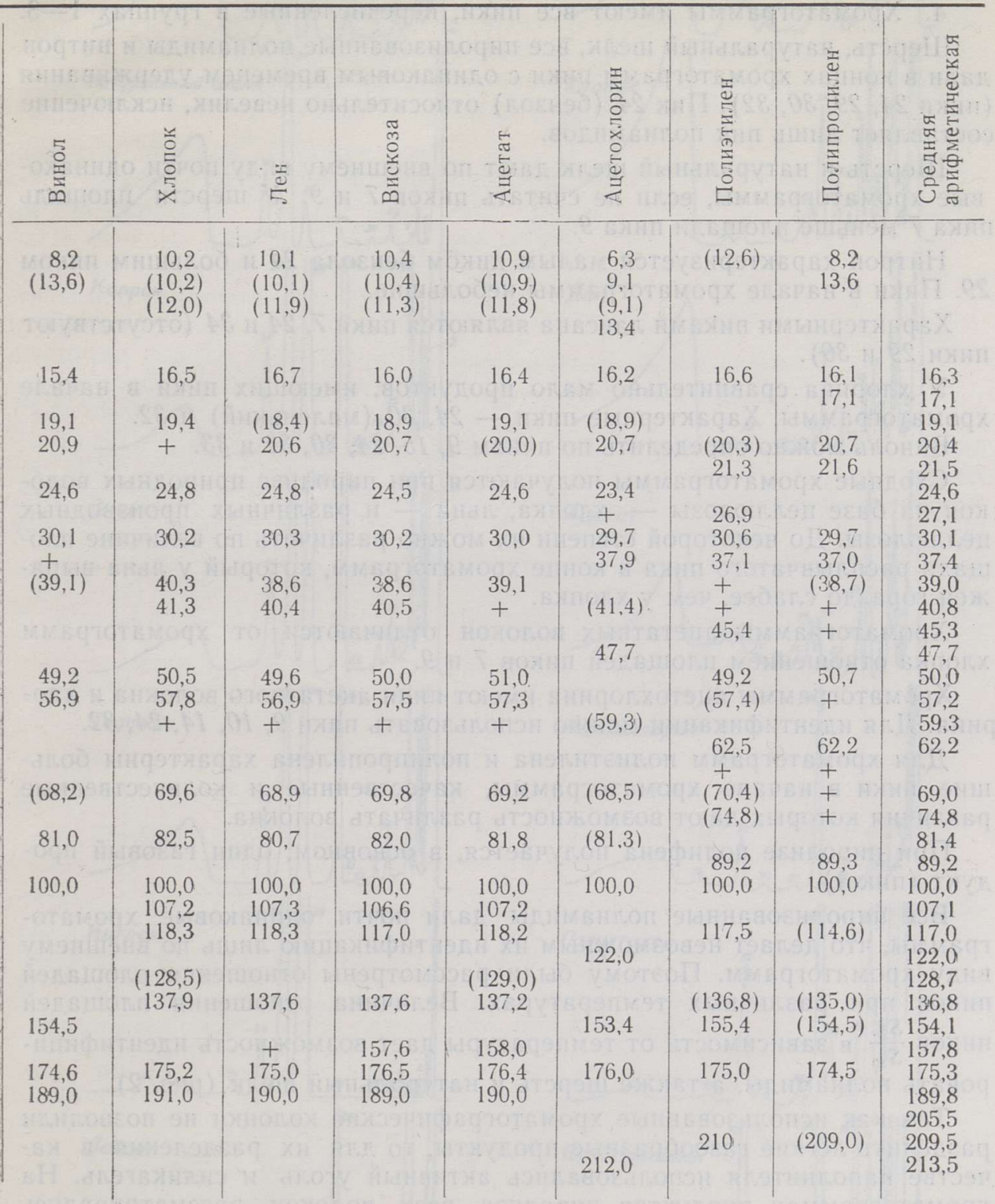

3. Знаком «+» обозначены малые пики, которые при параллельных опытах появлялись не всегда и которые можно использовать в качестве вспомогательных признаков.

4. Хроматограммы анида и вискозы на рисунках не изображены, так как они аналогичны хроматограммам капрона, энанта и ундекана (для анида), хлопка и льна (для вискозы). 
рые не имеют в конце хроматограммы расплывчатого пика, указанного в пункте 1 .

4. Хроматограммы имеют все пики, перечисленные в группах 1 -3.

Шерсть, натуральный шелк, все пиролизованные полиамиды и нитрон дали в концах хроматограмм пики с одинаковым временем удерживания (пики 24, 29, 30, 32). Пик 24 (бензол) относительно невелик, исключение составляет лишь пик полиамидов.

Шерсть и натуральный шелк дают по внешнему виду почти одинаковые хроматограммы, если не считать пиков 7 и 9 . У шерсти площадь пика 7 меньше площади пика 9.

Нитрон характеризуется малым пиком бензола 24 и большим пиком 29. Пики в начале хроматограммы небольшие.

Характерными пиками лавсана являются пики 7, 24 и 34 (отсутствуют пиики 29 и 30 ).

У хлорина сравнительно мало продуктов, имеющих пики в начале хроматограммы. Характерные пики - 24, 30 (маленький) и 32.

Виноль можно определить по пикам 9, 15, 24, 30, 32 и 33.

Сходные хроматограммы получаются при пиролизе природных волокон на базе целлюлозы - хлопка, льна - и различных производных целлюлозы. До некоторой степени их можно различить по величине площади расплывчатого пика в конце хроматограмм, который у льна выражен гораздо слабее, чем у хлопка.

Хроматограммы ацетатных волокон отличаются от хроматограмм хлопка отношением площадей пиков 7 и 9.

Хроматограммы ацетохлорнна имеют пики ацетатного волокна и хлорина. Для идентификации можно использовать пики 9, 10, 14, 24, 32.

Для хроматограмм полиэтилена и полипропилена характерны большие пики в начале хроматограммы, качественные и количественные различия которых дают возможность различать волокна.

При пиролизе полифена получается, в основном, один газовый продукт (пик 1).

Bce пиролизованные полиамиды дали почти одинаковые хроматограммы, что делает невозможным их идентификацию лишь по внешнему виду хрсматограмм. Поэтому были рассмотрены отношения площадей пиков при различных температурах. Величина отношения площадей пиков $\frac{S_{29}}{S_{30}}$ в зависимости от температуры дает возможность идентифицировать полиамиды, а также шерсть и натуральный шелк (рис. 2).

Так как использованные хроматографические колонки не позволнли разделить легкие газообразные продукты, то для их разделения в качестве наполнителя использовались активный уголь и силикагель. На хроматограммах продуктов пнролиза всех волокон рассматривалнісь отношения площадей пиков трех разделенных компонентов в колонке с активным углем при различных температурах пиролиза.

Рис. 3 иллюстрирует относительную величину площади пика метана в смеси его с $\mathrm{CO}$ и $\mathrm{CO}_{2}$, выраженную в процентах. Зависимость этой величины от температуры и ее отдельные значения могут быть использованы для идентификации волокон на основании предварительно составленных калибровочных кривых. Схематическая хроматограмма продук-

Рис. 1. Хроматограммы продуктов пиролиза волокон (без малых пиков, время удерживания которых указано в таблице). 

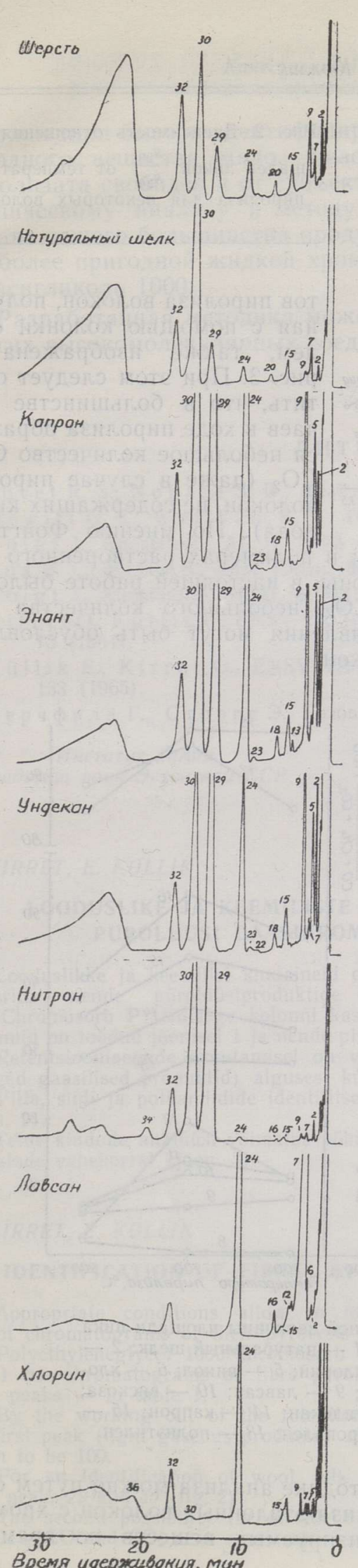
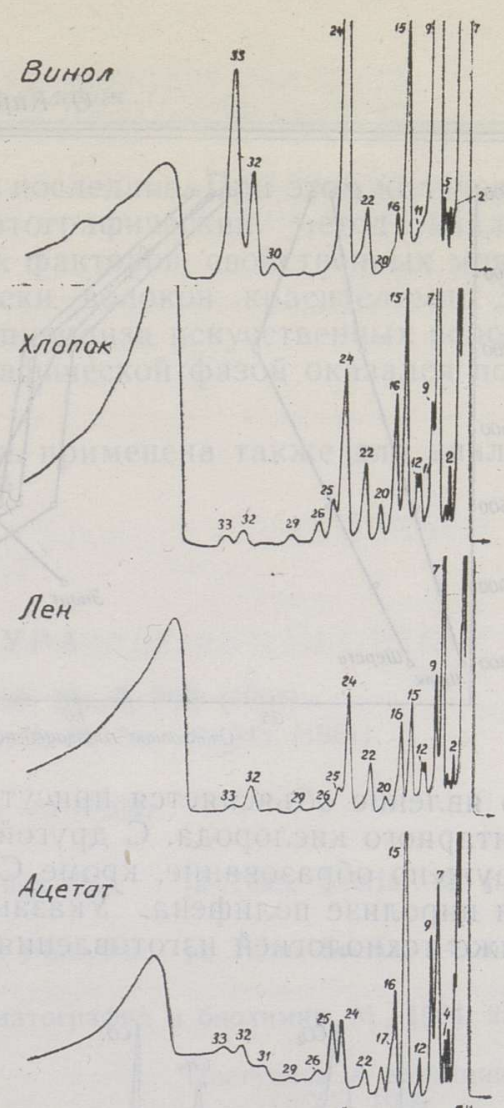

Aueтохnорин
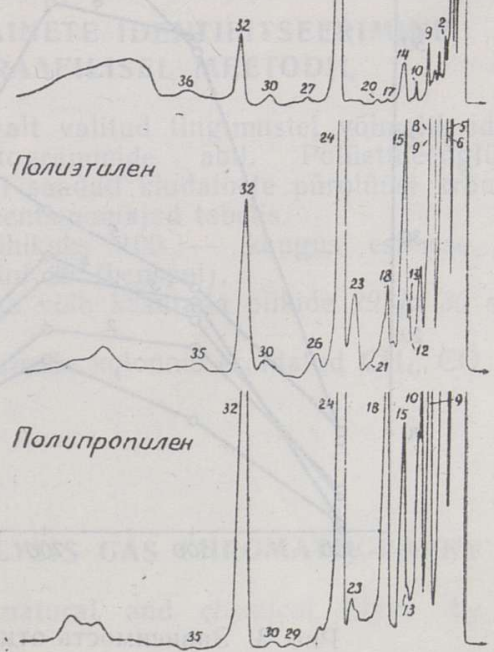

Полирен 


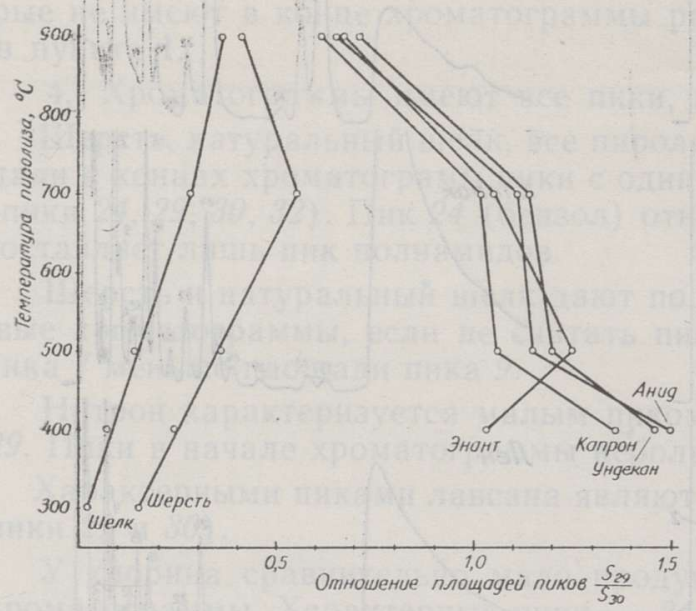

Рис. 2. Зависимость отношения плошадей пиков $\frac{s_{29}}{s_{30}}$ от температуры пиролиза для некоторых волокон.

тов пиролиза волокон, полученная с помощью колонки с углем, также изображена на рис. 3. При этом следует отметить, что в большинстве случаев в ходе пиролиза образуется небольшое количество СО и $\mathrm{CO}_{2}$ (даже в случае пиролиза волокон, не содержащих кислорода). По мнению Фойгта [3], это явление объясняется присутствием в полимерах растворенного элементарного кислорода. С другой стороны, в настоящей работе было обнаружено образование, кроме $\mathrm{CO}$ и $\mathrm{CO}_{2}$, неболышого количества $\mathrm{CH}_{4}$ при пиролнзе полифена. Указанные явления могут быть обусловлены также технологией изготовления волокон.

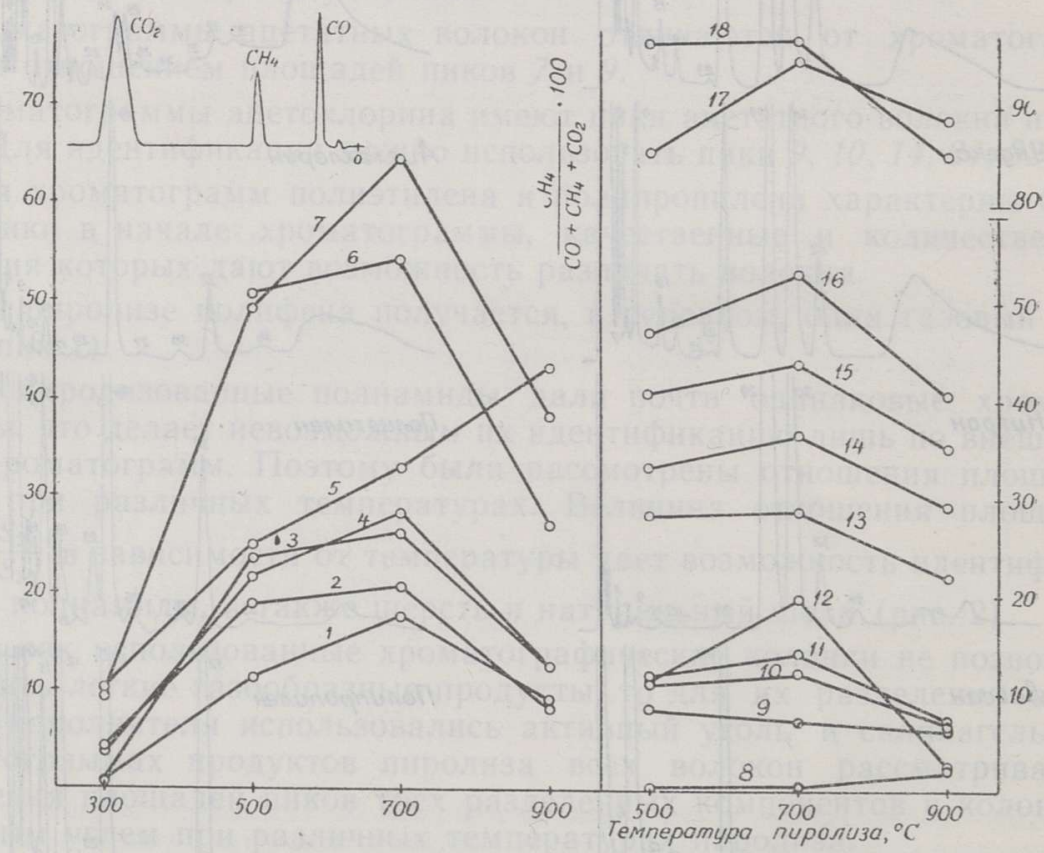

Рис. 3. Зависимость относительной величины площади пика $\mathrm{CH}_{4}$ от температуры пиролиза: 1 - натуральный шелк; 2 ацетат; 3 - шерсть; 4 - ацетохлорин; 5 - винол; 6 - хлорин; 7 - нитрон; 8 - полифен; 9 - лавсан; 10 - вискоза; 11 - хлопок; 12 - лен; 13 - ундекан; 14 - капрон; 15 анид; 16 - энант; 17 - полипропилен; 18 - полиэтилен.

Основываясь на разработанной методике анализа можнө путем сравнения хроматограмм продуктов пиролиза эталонных волокон с хроматограммами продуктов пиролиза анализируемых веществ по временам 
удерживания быстро идентифицировать последние. При этом количество исходното вещества мало. Газохроматографический метод анализа пиролизата свободен и от субъективных факторов, свойственных микроскопическому анализу и методу окраски волокон красителями. Для подавляющего большинства продуктов пиролиза искусственных волокон наиболее пригодной жидкой хроматографической фазой оказался полиэтиленгликоль 1000.

Разработанная методика может быть примененя также для анализа других высокомолекулярных соединений.

\section{ЛИ Т Е РА Т У Р А}

1. Juvet R. S., N o g a te S. D., Anal. Chem., 36, No. 5, 36R (1964).

2. Hew itt G. C., Whith a m B. T., The Analyst, 86, No. 10, 643 (1961).

3. Vo ig t J., Kunststoffe, 51, H. 1, 78 (1961).

4. C ox B. C., Ell is B., Anal. Chem., 36, No. 1, 90 (1964).

5. Voigt J., Kunststoffe, 51, H. 6, 314 (1961).

6. Kirret O., Kü11 ik E., ENSV TA Toimet. Füüs.-Mat. ja Tehn. Seeria, 13, nr. 1, 15 (1964)

7. Küllik E., Kirret O., ENSV TA Toimet. Füüs.-Mat. ja Tehn. Seeria, 14, nr. 1 , 133 (1965).

8. Бе р ч филд Г., С т ор р с Э., Газовая хроматография в биохимии, М., 1964, 234.

Ннститут химии

Академии маук Эстонской ССР
Постуінла в редакцию, $17 /$ XII 1965

\section{O. KIRRET, E. KULLIK}

\section{LOODUSLIKE JA KEEMILISTE KIUDAINETE IDENTIFITSEERIMINE PUROLUUSI GAASIKROMATOGRAAFILISEL MEETODIL}

Looduslikke ja keemilisi kiudaineid on sobivalt valitud tingimustel võimalik identifitseerida nende pürolüüsiproduktide kromatogrammide abil. Polüetüleenglükool 1000/Chromosorb P täidisega kolonni kasutamisel saadud kiudainete pürolüüsi kromatogrammid on toodud joonisel 1 ja nende piikide retentsiooniajad tabelis.

Retentsiooniaegade arvutamisel on võetud ühikuks 100 - kaugus esimese piigi (kerged gaasilised produktid) algusest kuni piigini 26 (bensool).

Villa, siidi ja polüamiidide identifitseerimiseks võib kasutada piikide 29 ja 30 suhet (joon. 2).

Teine kiudude analüüsi võimalus pōhineb aktiivsöe kolonnis eraldatud $\mathrm{CH}_{4}, \mathrm{CO}, \mathrm{CO}_{2}$ pindalade vahekorral (joon. 3).

\section{O. KIRRET, E. KULLIK}

\section{IDENTIFICATION OF FIBRES BY PYROLYSIS GAS CHROMATOGRAPHY}

Appropriate conditions allow to identify natural and chemical fibres by the use of chromatograms of their pyrolysis products.

Polyethyleneglycol $1000 /$ Chromosorb $\mathrm{P}$ were used as the column filling matter. In fig. 1 the chromatograms of fibre pyrolysis are presented, and the retention data of their peaks - in table 1.

By the working out of the retention data, the distance between the beginning of the first peak (light gaseous products) and the maximum of peak No. 26 (benzene) was taken to be 100 .

For an identification of wool, silk and polyamids one may use the relations of their peaks 29 and 30 (fig. 2).

The second possibility for an identification of fibres is based on the relations of the $\mathrm{CH}_{4}, \mathrm{CO}$ and $\mathrm{CO}_{2}$ peak areas separated in the activated coal column. 